\title{
Uso do GeoGebra como metodologia de ensino e aprendizagem
}

\author{
Karina Maria da Fonseca Luciano \\ Resumo

\begin{abstract}
Esse artigo tem por objetivo examinar as atividades de Cálculo Diferencial e Integral I centradas nos conceitos das teorias organizadas a partir de execução de atividades feitas em sala através do emprego do GeoGebra. As etapas da didática empregada serviram de base para a elaboração, execução e análise das atividades desenvolvidas com os estudantes do primeiro período do curso de Engenharia Elétrica. Com o desenvolvimento das aulas e a sequência do trabalho, é relevante citar o quanto tornou-se significativa a parceria entre a pesquisa e a docência, via projeto concomitante às atividades no ensino da matemática via cálculo diferencial e integral.
\end{abstract}

\section{INTRODUÇÃO}

A disciplina Cálculo Diferencial e Integral I constitui-se em um campo de conhecimento importante dentro da cultura científica moderna, especialmente, pelo seu potencial e sua utilização. Entretanto, o processo de ensino e aprendizagem se converte em um objeto de pesquisa na educação universitária, especialmente, pela problemática inerente às dificuldades encontradas para a compreensão de seus teoremas, pelo alto número de evasão e reprovação dos universitários e também pela falta de articulação entre os resultados da investigação. RUTHVEN (2002) considera as conexões existentes entre a investigação e o ensino recomendando uma colaboração entre os conhecimentos decorridos da investigação acadêmica e os conhecimentos decorridos da prática profissional - docência (RUTHVEN, 2002, p. 581).

Com a finalidade de requerer uma articulação coesa entre a investigação didática de cálculo e o ensino de cálculo no ensino superior, estabeleceu-se atividades com o emprego do GeoGebra, sendo concretizadas pelos mesmos com o auxilio da professora pesquisadora. Aos alunos que participaram dessa pesquisa, como não tinham noções prévias sobre o GeoGebra, foram dadas aulas onde o Software foi apresentado as principais ferramentas do software, sobretudo as ferramentas que seriam mais utilizadas ao se tratar os conceitos de cálculo.

\section{AS TECNOLOGIAS NO PROCESSO DE ENSINO E APRENDIZAGEM}

Por meio da técnica profissional docente, ressalta-se que, nos cursos de graduação, em especial os relacionados às engenharias, em grande parte das instituições, muito se tem falado sobre a inclusão digital

PALAVRAS-CHAVE: Matemática. Funções. Software.

${ }^{1}$ Mestranda em Engenharia e Gestão de Processos e Sistemas, Instituto de Educação Tecnológica(Ietec) Professora de Cálculo Diferencial e Integral na Faenge-Uemg, Professora de Cálculo Diferencial e Integral, Geometria Analítica e Álgebra Linear no Instituto Ensinar do Brasil

doi:10.12957/cadmat.2016.22585 
e a grande influência que a tecnologia traz para as metodologias educacionais. Entretanto, poucos aproveitam esses instrumentos tecnológicos nas disciplinas das áreas de Ciências Exatas.

Portanto compete ao educador propiciar aos estudantes uma aprendizagem significativa de assuntos característicos à disciplina Cálculo Diferencial e Integral I, e, ao mesmo tempo, esse necessita ser de relevância para que aconteça a concepção de noções e de conceitos matemáticos. Assim sendo, o emprego de recursos tecnológicos concede uma visualização aceitável dos conceitos matemáticos, o que pode colaborar na obtenção de seus significados (GODINO, BATANERO \& FONT, 2007). Ainda, pode- se dizer que o emprego dos recursos tecnológicos pode ser encarado como uma metodologia de ensino e aprendizagem das noções/conceitos matemáticos possibilitando a solução de diversas situações problema. Neste raciocínio, pode-se dizer que deseja-se desenvolver um estudo, que faz parte de uma pesquisa mais ampla, que tende colaborar com a produção, aplicação e análise de recursos didáticos através da utilização e manuseio de tecnologias como metodologia de ensino no processo de ensino e aprendizagem, estas precisarão estar bem articuladas com os aspectos teóricos, práticos e investigativos da disciplina Cálculo Diferencial e Integral I, levando em consideração os resultados de estudos

desenvolvidos dentro da linha de pesquisa tecnologias aplicadas à Educação Matemática.

A pesquisa colabora para a ampliação profissional da professora-pesquisadora, expandindo seus conhecimentos teóricos, práticos e investigativos com relação ao processo de ensino e aprendizagem da Matemática e, em especial, a disciplina Cálculo Diferencia e Integral I. Com isso ocasiona a obtenção das habilidades imprescindíveis ao trabalho em grupo através das interpelações presenciais e/ou virtuais, considerando o aprimoramento das capacidades demandadas para a concretização de tarefas colaborativa pelos educadores. Confirmando essa ideia, Azevedo fala que:

[...] a sociedade hoje requer um sujeito que saiba contribuir para o aprendizado
do grupo de pessoas do qual ele faz parte, quer ensinando, quer aprendendo,
respondendo ou perguntando. É a inteligência coletiva do grupo que se deseja
por em funcionamento, a combinação de competências distribuídas entres seus
integrantes, mais do que a genialidade de um só (AZEVEDO, 2006, p.15).

Do mesmo modo, “o uso de tecnologias significa maior dedicação à tarefa e à apreensão, ou seja, de um lado, o ambiente da sala de aula se modifica e, de outro, o trabalho do educador ao mesmo tempo passa por alterações, especialmente no sentido de maior ativação do educador” (MERCADO, 1998,p.15).

Por tanto, compete à instituição universitária o ingresso das tecnologias de comunicação e informação e a direção de técnica de alteração do desempenho do educador que proporcione ao estudante buscar corretamente a informação em diferentes fontes e que assim possa continuar no processo, estando consciente das verdadeiras competências da tecnologia, e de todo seu potencial e também de suas restrições, para que assim consiga escolher qual é a melhor forma de utilização a ser implantada na solução de um conteúdo especifico, colaborando para o melhoramento do processo ensino e aprendizagem, através de uma nova prática pedagógica.

Entretanto, para alcançar o proposto acima foi necessário ter uma coerente união entre a pesquisa e a prática educadora no campo universitário, compreendendo que essas precisam ser observadas sendo uma "via de mão dupla", ou seja, os dados das pesquisas colaborarão para a coordenação da docência e os conhecimentos do docente mostrarão novos jeitos para a ampliação e o desenvolvimento da pesquisa universitária na esfera da Educação Matemática. 


\title{
3 PESQUISAS CONCRETIZADAS EM DIDÁTICA DO CÁLCULO DIFERENCIAL E INTEGRAL I
}

A ampla variedade de pesquisas concretizadas a respeito da formação de educadores de matemática anunciadas nos tópicos dos Handbook com relação a esse tema (JAWORSKI e GELLERT, 2003; ZASLAVSKY, CHAPMAN e LEIKIN, 2003; PONTE e CHAPMAN, 2006) tanto nas revistas

quanto nos anais de congressos confirmam a obrigação de centralizar o estudo no conteúdo matemático exclusivo que se ambiciona pesquisar. Esse rumo se aproveita também às pesquisas sobre o procedimento de ensino e aprendizagem da Matemática nos diversos cursos, principalmente nas áreas de Ciências Exatas e Tecnológicas.

A pesquisa, particularmente sobre o cálculo, é apreciável a observação de determinados aspectos da mesma que devem ser úteis ao trabalho proposto, sobretudo no que se relaciona à metodologia de ensino e aprendizagem, observada nos primeiros anos dos cursos universitários.

Tall (1991) ao falar sobre a mudança do pensamento matemático elementar para o pensamento matemático avançado advertiu que:

\begin{abstract}
O câmbio do pensamento matemático elementar para o avançado envolve uma significativa transição: desde a descrição à definição, desde o convencimento à demonstração de maneira lógica baseada nas definições. Essa transição requer uma reconstrução cognitiva, que se manifesta durante os conflitos iniciais dos estudantes universitários com as abstrações formais enfrentadas por eles no primeiro ano da universidade (p.20).
\end{abstract}

Enquanto professora de matemática em especial da disciplina Cálculo Diferencial e Integral I, na universidade pública e na universidade privadas, tem-se percebido os problemas que os alunos exibem durante o desenvolvimento e aprendizagem da referida disciplina.

O GeoGebra tem duas janelas de trabalho: a janela geométrica e a janela de álgebra. A janela geométrica, de cor branca, é o lugar onde os objetos são erguidos. É possível pintar os objetos, bem como aumentar a espessura das linhas, medir ângulos, medir distâncias, estabelecer funções, definir limites, descobrir retas tangentes, entre diferentes outras aproveitamentos.

As oportunas propriedades do GeoGebra permitem a concepção de paisagens para atividades investigativas, os quais o estudante consegue constatar propriedades de um desenho em um procedimento muito rápido. Percebe-se que nas atividades investigativas existe uma metodologia na qual o estudante é chamado a abrir os olhos a perguntas do tipo: “O que vai ocorrer se...?”, encorajando-o a buscar respostas às suas perguntas e ao mesmo tempo ocorre a busca por descobertas. Mediantes estas questões a sala de aula modifica-se em uma atmosfera de aprendizagem em que o estudante é instigado a um processo de exploração e explicação (SKOVSMOSE, 2000).

Almejam-se empregar este enfoque concentrando nas investigações, pois por meio delas é possível “contribuir para concretizar a relação entre situações matemáticas, desenvolver capacidades, tais como a visualização espacial e o uso de diferentes formas de representação" (PONTE 2003, p.71). Ambiciona-se portanto desenvolver atividades desse caráter onde seja possível abrir os olhos dos estudantes para que assim possam ter maior interesse pela disciplina cálculo e assim venham a perceber os aspectos mais importantes da Matemática. 


\section{METODOLOGIA}

Existem educadores, que para lecionar os conteúdos, estabelecem práticas pedagógicas diferentes, ou seja, por meio de comprovações e contextualizações, gerando uma apreensão dos aspectos sociais, linguísticos e cognitivos no ensino da Matemática, assim conseguem demonstrar a relação existente entre a Geometria com a Aritmética e com a Álgebra (BRASIL, 1998, p.21).

Diante essa combinação de maneiras e atitudes de se ensinar os conteúdos matemáticos dentro da sala de aula, o Parâmetros Curriculares Nacionais (PCN) de Matemática (BRASIL, 1998, p.37) alega que os educadores necessitam apresentar nitidez de suas oportunas percepções sobre a Matemática, já que nas práticas realizadas dentro da sala de aula, as escolhas pedagógicas, a escolha de objetivos e conteúdos de ensino bem como as formas de avaliação permanece intimamente vinculada a essas concepções.

Dessa maneira, com um repensar, o docente pode começar uma técnica de transformação conceitual, indo de um modelo para outro, e buscar meios para resolveras falhas encontras no ensino da Matemática, em específico no ensino do conteúdo de Cálculo Diferencial e Integral I, encontrando processos que admitam conceber sua ação de educador com todos os seus vários objetivos, buscando, assim maneiras que gerem a aprendizagem e que possibilitem aos alunos o desenvolver de um pensamento analítico e ao mesmo tempo dedutivo que seja capaz de solucionar as situações sugeridas em Cálculo. Portanto, admitir diferentes oportunidades de trabalho em sala é essencial para que o educador estabeleça sua práticapedagógica.

Como a importância está em estabelecer o papel do educador dentro do processo de prova num espaço dinâmico para constituir explicações a respeito de como sucede este processo isto nos induziu a apoiar um método qualitativo, tanto na análise quanto na coleta de dados. Portanto, escolheu-se por realizar uma experiência de ensino que, de acordo com Araújo e Borba (2004, p. 7), é uma pesquisa em que "atividades pedagógicas são propostas a estudantes de forma que o pesquisador-professor possa 'ouvir' de forma detalhada a Matemática desenvolvida por estudantes”. Assim sendo, os estudantes trabalharam com atividades escolhidas e a partir das observações foi possível concretizar a construção de uma teoria.

Além do mais, em uma pesquisa de ensino é possível acompanhar o entendimento que o aluno consegue desenvolver e ainda estabelecer sua interação com o educador, enquanto estabelecem as intervenções concretizadas por ele, o que numa sala de aula fica mais complicado de ser compreendido. À medida que foram desenvolvidas atividades em sala de aula tendo como apoio o livro didático, a educadora ia estabelecendo intervenções no desenvolvimento das atividades, como por exemplo, ao perguntar a um determinado aluno como foi possível estabelecer o limite de uma determinada função. Alguns conseguiam explicar de maneira clara, outros ficavam indecisos e alguns diziam que sabiam. A educadora com auxilio do quadro mostrava aos alunos como era possível estabelecer o limite da função ora por meio de racionalização ora por meio do teorema do confronto bem como outras propriedades eram demonstradas a medida da necessidade.

Após explicações e intervenções os estudantes conseguiram estabelecer de maneira correta o emprego dos teoremas e propriedades relacionadas aos limites de funções no papel, a partir dai seguiu-se para o desenvolvimento das atividades no software GeoGebra, houve algumas dúvidas com relação ao emprego das funcionalidades do software por isso a educadora ministrou uma aula para conhecimento e explanação das funções do software. Após algumas aulas os estudantes conseguiram plotar as funções de maneira correta bem como determinar domínio, imagem das funções trabalhadas, foi possível ainda trabalhar a teoria funções pares e ímpares. Ao tentar determinar o limite das funções os estudantes 
precisaram compreender os conceitos de limites laterais, assim como a existência ou não de limite para uma determinada função. Ainda dentro dos conceitos abordados foi possível entender o significado de assíntotas horizontais e verticais dadas uma função e por fim trabalhou-se o conceito de continuidade, foi explanado o conceito de uma função ser contínua quando o seu gráfico não exibe interrupções, isso é,o gráfico é desenhado sem que haja espaço entre o traço. Assim sendo, pode-se dizer que uma função f é contínua em um determinado ponto $\mathrm{x}=\mathrm{a}$, quando é definida em "a" e as estimações de $\mathrm{f}(\mathrm{x})$, para valores de $\mathrm{x}$ próximos ao ponto " $\mathrm{x}=\mathrm{a}$ ", permaneçam próximos de $\mathrm{f}(\mathrm{a})$.

O embasamento da atividade incide em assumir como tema de partida uma ou varias situaçãoproblema na compreensão de ensino, aprendizagem e avaliação de Matemática por meio da resolução de determinados problemas. Essa compreensão é percebida como um procedimento de ensino, em que uma dificuldade é tema de partida e segue-se rumo a aprendizagem e a constituição de conhecimento que acontecerá através de sua resolução. Educador e estudantes, unidos, conseguem desenvolver o trabalho e com isso a aprendizagem ocorre de maneira colaborativa em sala de aula.

[...] Dessa forma, o ensino-aprendizagem de um tópico matemático começa com um problema que expressa aspectos-clave desse tópico e técnicas matemáticas devem ser desenvolvidas na busca de respostas razoáveis ao problema dado. A avaliação do crescimento dos alunos é feita continuamente, durante o processo de resolução de problemas (ALLEVATO, ONUCHIC E JANH, 2010, p. 192-193).

Fundamentado na concepção e na literatura particular pertinente ao processo de ensino e aprendizagem de Cálculo exibimos, a seguir, as atividades planejadas e desenvolvidas pelos alunos do ensino superior, sendo que antes de começar o estudo foi oferecido aos alunos uma apresentação sobre as propriedades e as interfases que o software GeoGebra possui, sendo que esta foi a ferramenta empregada em todo o procedimento de ensino e aprendizagem de Cálculo Diferencial e Integral I.

\section{Atividades exploratórias}

Para a concretização das atividades, o software GeoGebra foi baixado no site gratuitamente. https://www.geogebra.org/download Atividades:

Funções

$>$ Objetivos:

$>$ Determinar o Domínio das funções algébrica e graficamente.

$>$ Determinar a imagem das funções

$>$ Diferenciar os gráficos das Funções Pares e Ímpares.

1)Esboce o gráfico das funções abaixo e encontre o domínio de cada função

a) $f(x)=2 x-1$

b) $f(x)=2 x^{2}$

c) $f(x)=x /(3 x-1)$

d) $f(x)=(5 x+4) /\left(x^{2}+3 x+2\right)$ 


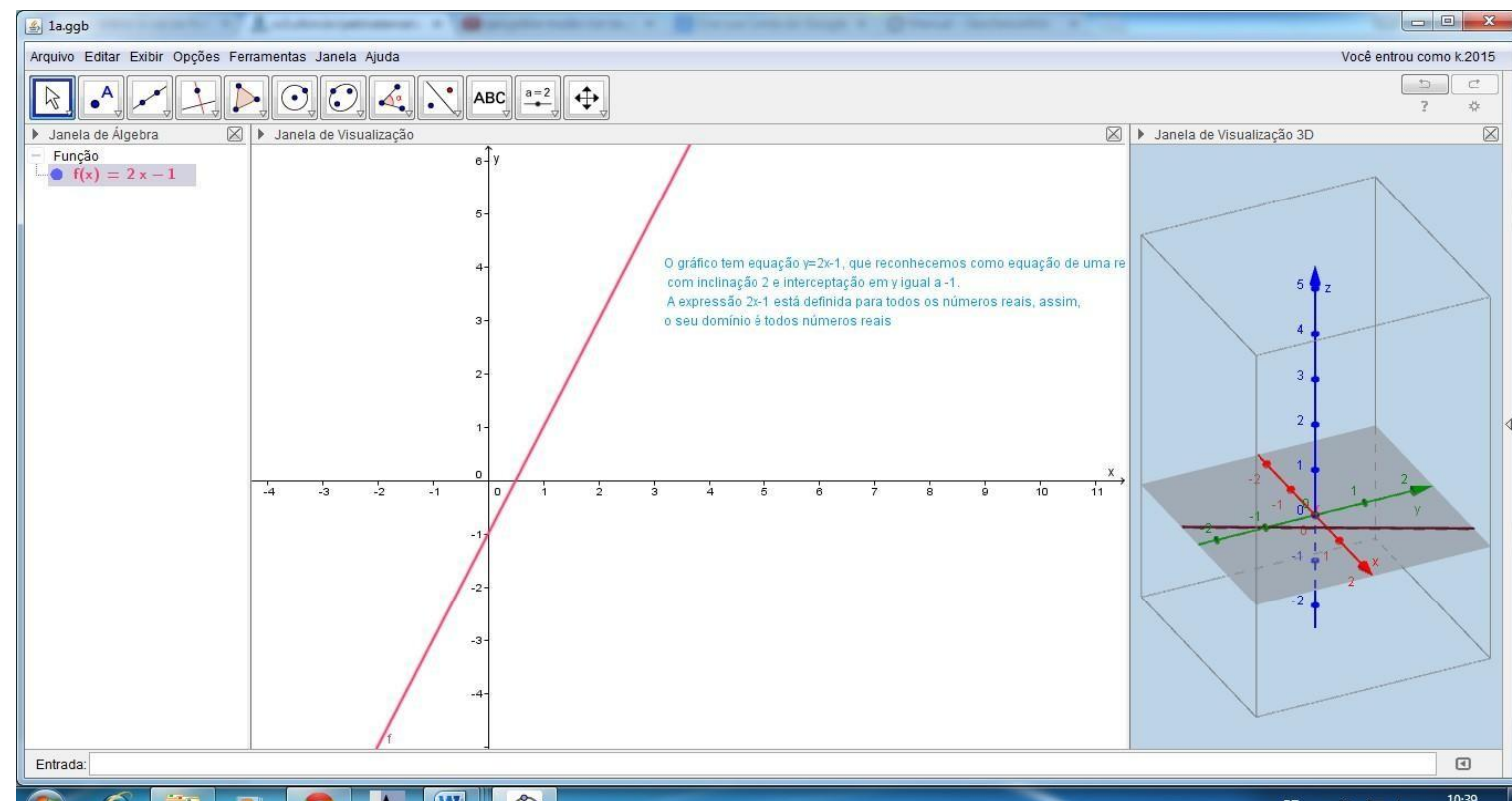

\section{(4) 6 可 D}

Figura 1:Domínio de $\mathrm{f}(\mathrm{x})=2 \mathrm{x}-1$

2)Determine a imagem das funções abaixo:

a) $f(x)=-4 x+1$

b) $f(x)=x$

c) $f(x)=1 / x^{3}$

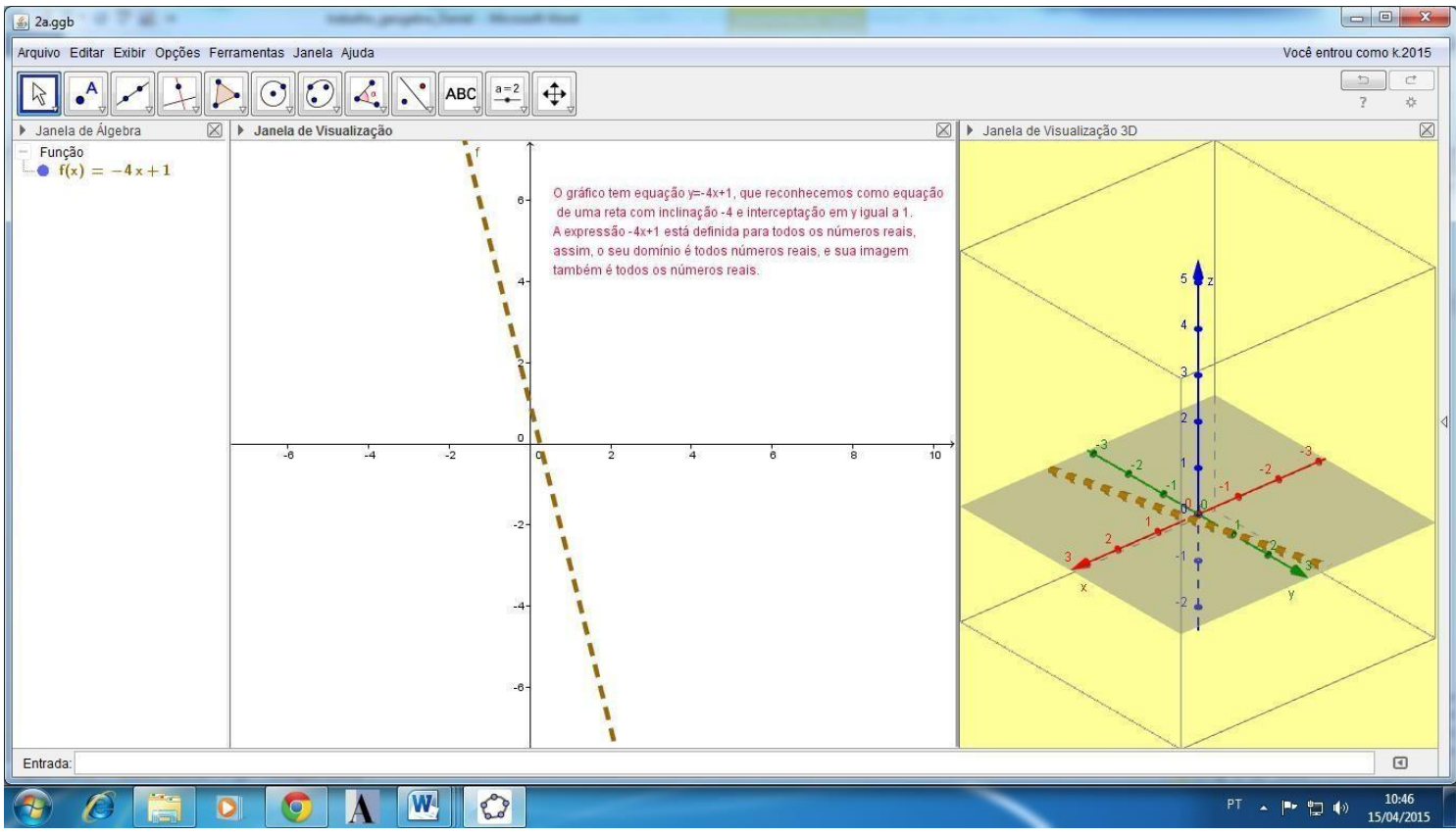

Figura 2:Imagem de $f(x)=-4 x+1$

3)Verifique se a função abaixo é par ou ímpar
a) $f(x)=2 x^{2}$
b) $f(x)=3 x^{3}$ 
c) $f(x)=x$

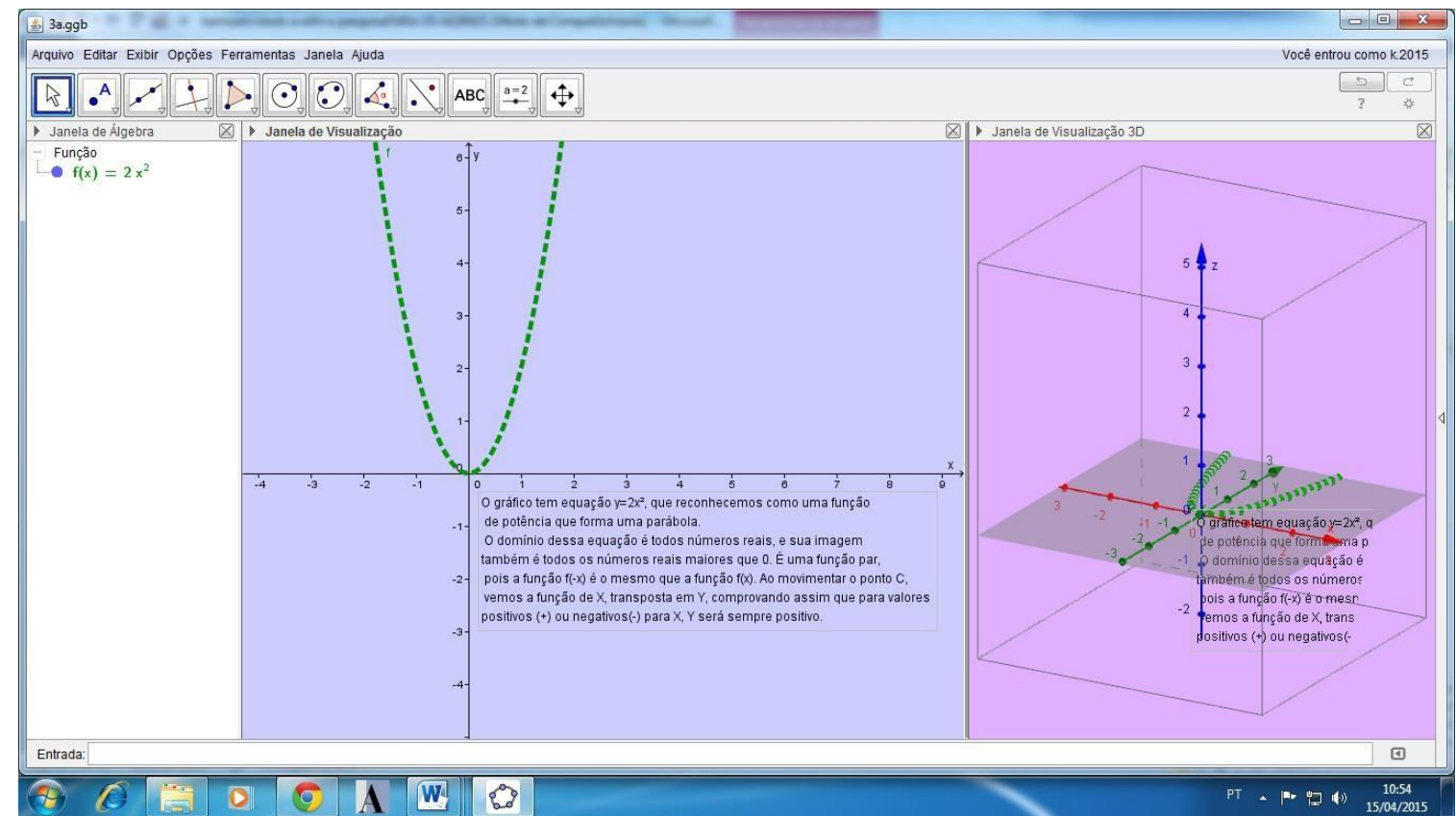

Figura 3:Função par

\section{Limites}

Noção intuitiva de limite e continuidade de uma função utilizando o software GeoGebra Objetivos:

$>$ Visualizar graficamente o limite de uma função, bem como os limites laterais manuseando a ferramenta "mover" (comando da $1^{\text {a }}$ caixa de ferramentas);

$>$ Estudar a existência ou não do limite no ponto; - Verificar a continuidade de uma função em um determinado ponto;

$>$ Esboçar funções definidas por mais de uma expressão utilizando o "Se", no comando de entradas;

$>$ Descobrir valores que tornam a função contínua fazendo uso da ferramenta "Seletor" (comando da $10^{\mathrm{a}}$ caixa de ferramentas) do GeoGebra e de manuseio com a ferramenta "mover" (comando da $1^{\text {a }}$ caixa de ferramentas);

\section{1 - Determinar o limite}

a)

$$
\lim _{x \rightarrow 2} \frac{x^{2}+x-6}{x-2}
$$

b)

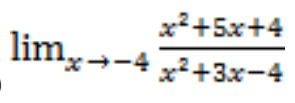

$$
\begin{aligned}
& \lim _{x \rightarrow 2} \frac{x^{2}-x+6}{x-2} \\
& \text { c) } \lim _{x \rightarrow 4} \frac{x^{2}-4 x}{x^{2}-3 x-4}
\end{aligned}
$$


e) $\lim _{x \rightarrow-1} \frac{x^{2}-4 x}{x^{2}-3 x-4}$

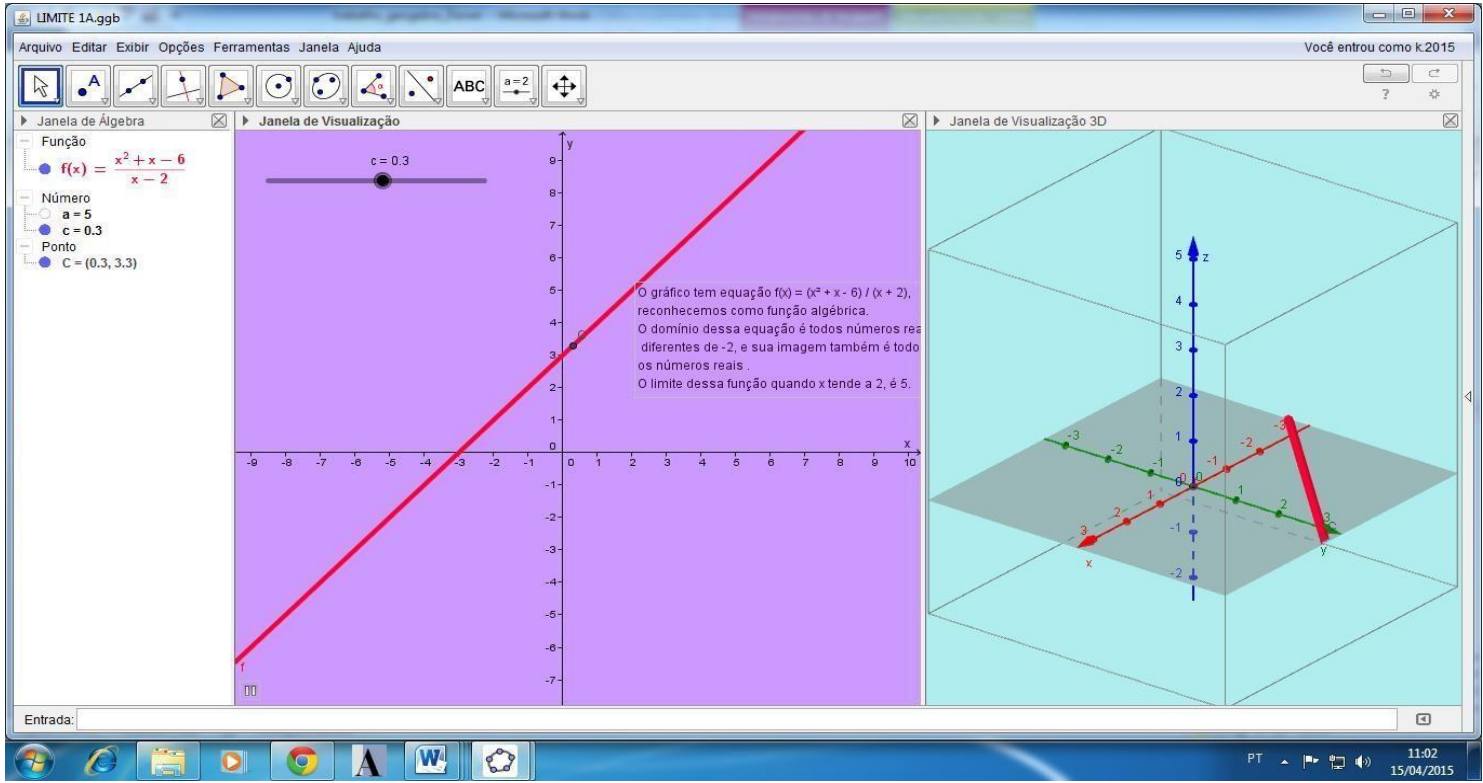

Figura 4: $\lim _{x \rightarrow 2} \frac{x^{2}+x-6}{x-2}$

Continuidade de funções

1)Utilize o GeoGebra para plotar os gráficos e discuta a continuidade das seguintes funções:

a) $f(x)=\left\{\begin{array}{l}\frac{1}{x^{2}}, \text { se } x \neq 0 \\ 1, \text { se } x=0\end{array}\right.$

b) $f(x)=\left\{\begin{array}{l}e^{x}, \text { se } x<0 \\ x^{2}, \text { se } x \geq 0\end{array}, a=0\right.$

c) $f(x)=\left\{\begin{array}{l}1+x^{2}, \text { se } x<1 \\ 4-x, \text { se } x \geq 1\end{array}, a=1\right.$

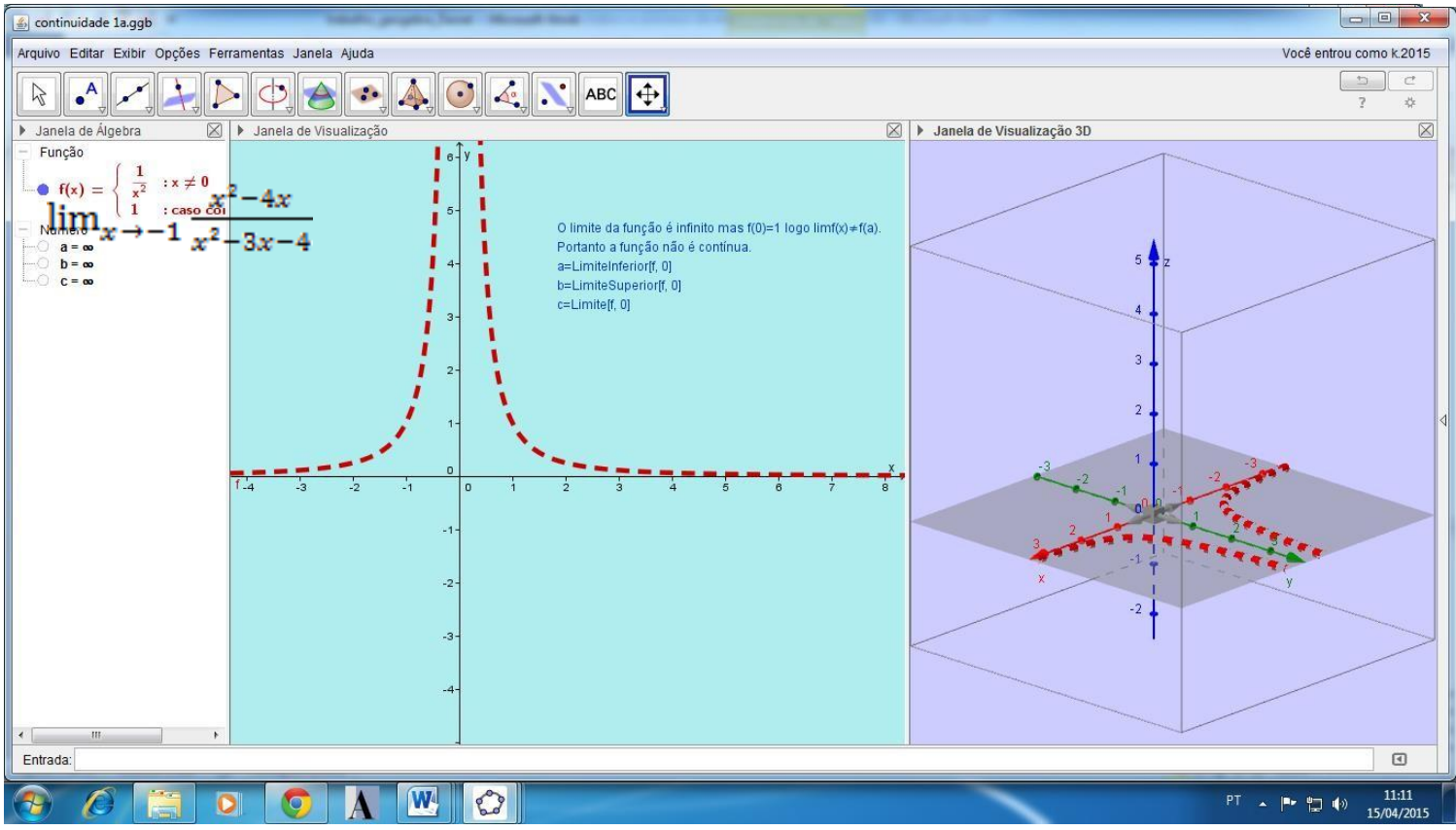

Figura 5:Função descontinua 


\section{Assíntotas}

1) Encontrar as assíntotas de uma função

a) $f(x)=\frac{3 x^{2}-x-2}{5 x^{2}+4 x+1}$

b) $f(x)=\frac{\sqrt{2 x^{2}+1}}{3 x-5}$

c)

$f(x)=\frac{x}{x+4}$

d) $f(x)=\frac{x-9}{\sqrt{4 x^{2}+3 x+2}}$

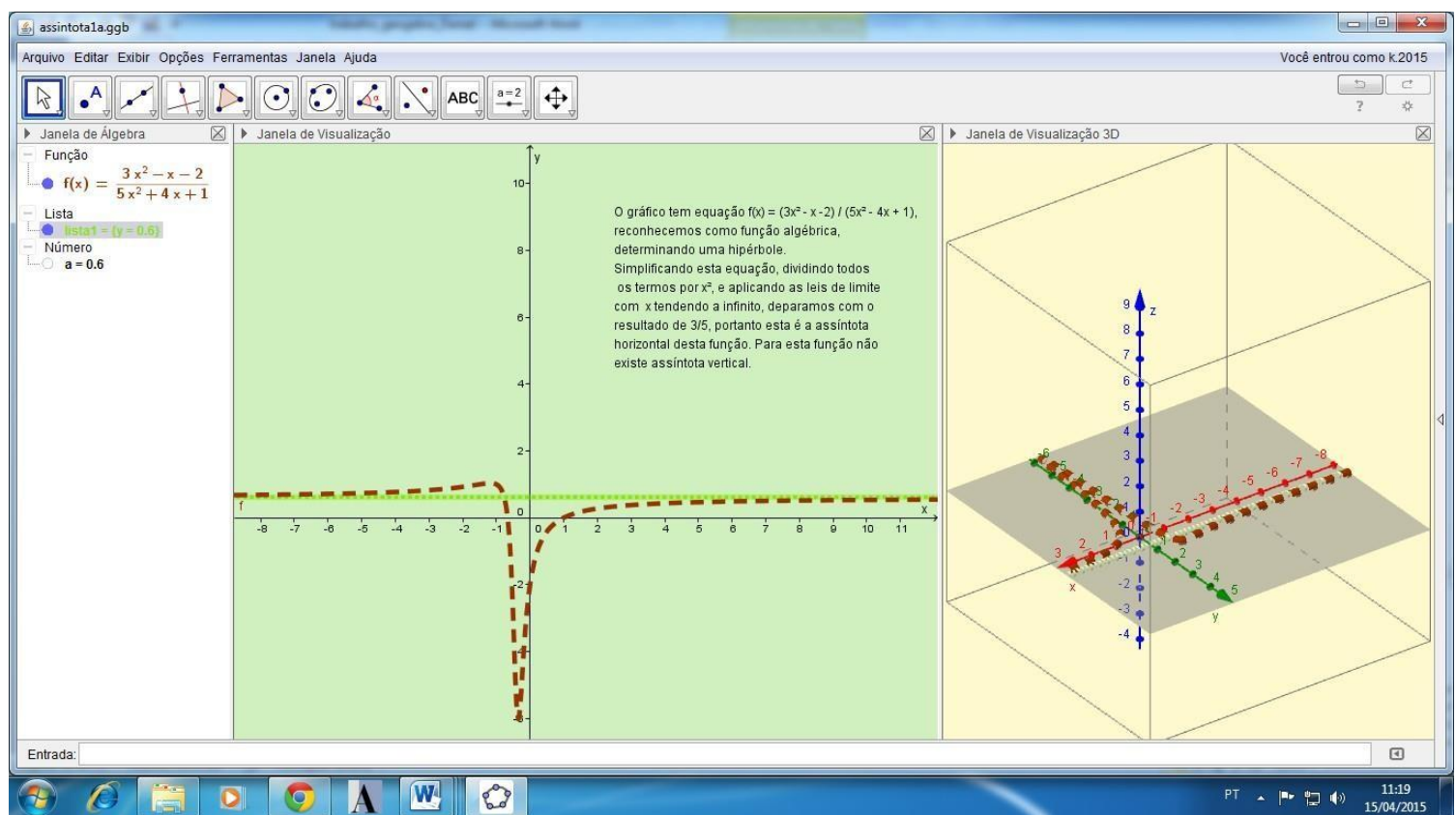

Figura 6: Assíntota de $f(x)=\frac{3 x^{2}-x-2}{5 x^{2}+4 x+1}$

\section{Período de realização da atividade: 20 horas/aula Avaliação}

A aprendizagem dos estudantes será medida oralmente no período das discussões e também por escrito através de suas observações realizadas na folha de atividades, levando em conta os objetivos sugeridos pela aula.

\section{DISCUSSÃO DAS ATIVIDADES}

Dentro da análise realizada foi possível verificar que houve participação e comprometimento de todos os estudantes sendo que estes avaliaram a atividade relevante como metodologia de ensino, os estudantes recomendaram a ampliação da carga horária destinada às práticas com utilização de software. Segue uma breve análise da atividade desenvolvida:

A atividade foi desenvolvida pelos estudantes em um período de 2 meses, durantes esse período alguns alunos procuram-me tanto em sala de aula como também foi disponibilizado e-mail para contanto onde foi possível interagir ainda mais como os alunos podendo assim buscar solucionar dúvidas. 
Esperava-se que os estudantes visualizassem os tipos de funções, domínio, imagem, bem como fosse possível classificar uma função como par ou impar, limites, continuidade e assíntotas de funções. Para encontrar o domínio e a imagem das funções era preciso que os estudantes plotassem o gráfico, analisassem que tipo de função estão trabalhando bem como a existência de alguma restrição para domínio ou imagem da função trabalhada. Quanto à classificação em par ou impar era necessário analisar a simetria do gráfico com relação ao eixo x e com relação ao eixo y. Na análise dos limites, além de se esperar que os estudantes soubessem plotar o gráfico corretamente, era necessário que estes calculassem os limites laterais e, por fim, o limite da função. Já na atividade sobre continuidade de uma função os estudantes plotaram funções definidas por partes e tiveram que calcular os limites laterais. Ao fazerem isso foi possível observar que o limite à direita é diferente do limite à esquerda, o que implica em limite da função indefinido, ou seja, não existe limite. Desta maneira, foi possível chegarem a conclusão que a função não era contínua.

Outro assunto importante a ser ressaltado é a etapa da construção das atividades para muitos alunos que voltaram a estudar depois de um grande período longe da escola foi um grande desafio, pois estes tiveram grande dificuldade em utilizar as ferramentas do software, já para outros o emprego das ferramentas foi de fácil manuseio e conseguiram executar todas as atividades sem nenhum problema. A maior dificuldade dos alunos foi ao que diz respeito à continuidade e a determinação das funções. Com relação às ferramentas do software foi possível observar que os estudantes tiveram dificuldades para utilizar a caixa de entrada, de fazer observações em relação ao gráfico em 3D e de utilizar corretamente a janela de visualização em propriedades, pois nesta janela é possível alterar cor, estilo, álgebra, avançado, programação e básico. Em estilo é possível modificar espessura da linha, opacidade do traço, estilo de linha e estilo das linhas escondidas como invisível, tracejado ou inalterado. Já em avançado aparece a condição para exibir objeto(s), onde é possível selecionar três cores padrão o vermelho, verde e azul, podendo permitir ou não a seleção em uma das três localizações, ou seja, janela de visualização, janela de visualização 2 e janela de visualização 3D. No básico é possível exibir ou ocultar objeto, rótulo e rastro, fixar ou não objeto e por fim definir como objeto auxiliar.

$\mathrm{Na}$ atividade de funções foi solicitado aos estudantes que analisassem o domínio a imagem e classificar as funções em par ou ímpar. A maioria dos estudantes conseguiu alcançar o objetivo proposto, alguns tiveram dificuldades, mas ao realizar discussões em grupo foi possível solucionar essas dificuldades. Na atividade sobre limites, continuidade e assíntotas, alguns alunos calcularam o limite de maneira errada, pois plotaram o gráfico de maneira errada ou não souberam interpretar o mesmo. Ao ser discutida a questão com o aluno, foi mostrado a ele o que havia errado e porque, assim foi possível elevar seu grau de conhecimento.

Finalmente, foi possível abordar e comprovar definições como domínio, imagem, classificação, limites, continuidade e assíntotas das funções de maneira teórica e visual isso proporcionou aos alunos uma aprendizagem mais significativa destes conceitos.

\section{CONCLUSÕES}

O afastamento entre a "teoria" e a "prática", entre as implicações da verificação acadêmica e o processo de ensino de Matemática, é um assunto de meditação freqüente em Ruthven (2002). O autor pondera as conexões entre a investigação e o ensino, sugerindo uma maneira de haver certa cooperação entre as informações decorridos da pesquisa acadêmica e as informações decorridas da prática profissional. "Uma preocupação particular se refere a como pode ser promovida uma maior sinergia entre 
essas duas práticas específicas, suas formas características de conhecimento e os processos associados de criação de conhecimento"(RUTHVEN, 2002, p. 581).

A junção coesa entre a teoria e a prática por meio da investigação incide em um objetivo a ser adquirido na educação. Pondera-se que tantas vezes a teoria colabora para o desenvolvimento da pesquisa, quanto os resultados das investigações colaboram para o acréscimo da teoria uma vez que são aplicados à prática profissional do professor e para seu melhoramento. Essa juntura pode se resumir em extraordinárias aprovações para a área de Educação Matemática.

No desenvolvimento da atividade de Cálculo com a utilização do GeoGebra, os universitários conseguiram fazer observações, fizeram algumas conjecturas, de modo a legitimá-las. A análise aconteceu de maneira qualitativa a partir das observações e do registro dos comentários das atividades realizadas pelos estudantes em concordância com a análise dos resultados das pesquisas efetuadas em didática do Cálculo.

A parte visual foi amplamente explorada nas atividades realizadas. Averiguou-se que depois de realizar os gráficos no GeoGebra, os estudantes enunciaram conhecimentos intuitivos sobre funções, e foram aos poucos construindo novos conhecimentos. Também foram instituídas algumas relações entre os conceitos antecedentes pautados com a atividade (funções, domínio, imagem, classificação de uma função par ou impar, limites, continuidade, assíntotas e representações gráficas.), reproduções das figuras visualmente, junção das configurações geométricas e algébricas e determinação das dificuldades encontradas pelos estudantes. Os resultados puderam proporcionar informações que nos permitirá meditar o potencial do emprego e utilização do software GeoGebra na preparação e desenvolvimento de atividades designadas à apreensão dos significados de elementos matemáticos e didáticos no âmbito da Matemática nas universidades.

\section{REFERÊNCIAS}

ALLEVATO, N. S. G; ONUCHIC, L. R.; JANH, A. P. (2010). O computador no ensinoaprendizagem-avaliação de matemática: reflexões sob a perspectiva de resolução de problemas. In: JHAN, A. P.; ALLEVATO, N. S. G. (Org.). Tecnologia e educação matemática: ensino, aprendizagem e formação de professores. Recife: SBEM, pp. 192-193.

AZEVEDO, W. (2006). Panorama atual da educação a distância no Brasil. Disponível em:http://www.aquifolium.com.br/educacional/artigos/panoread.html. acesso em: 18 de maio de 2006.

BRASIL. MEC. SEF. Parâmetros Curriculares para o Ensino Fundamental. Brasília: Ministério da Educação, 1998.

BORBA, M. C.; ARAÚJO, J. L. (Org.) Pesquisa Qualitativa em Educação Matemática. Belo Horizonte: Autêntica, 2004.

GODINO, J. D.; BATANERO, C.; FONT, V.The onto-semiotic approach to research in mathematics education.ZDM. The International Journal on Mathematics Education, Vol. 39 (1-2): p.127-135, 2007.

JAWORSKI, B.; GELLERT, U. Educating new mathematics teachers: integrating theory and practice, and the roles of practising teachers. In: BISHOP, A. J. et al. Second international handbook of mathematics education. Dordrecht: Kluwer, 2003.

MERCADO, L. P. L. (1998). Formação Docente e Novas Tecnologias. Universidade Federal de Alagoas. 
IV Congresso RIBIE, Brasília.

PONTE,J. P.(2003). Investigar, ensinar e aprender. Actas do ProfMat 2003 (pp.25-39). Lisboa:APM. Disponível em: <http://www.educ.fc.ul.pt/docentes/jponte/docs-pt/03Ponte(Profmat).pdf>.Consultado em 22 de julho de 2011.

PONTE, J. P.; CHAPMAN, O. (2006). Mathematics teachers' knowledge and practices. In: GUTIERREZ, A.; BOERO, P. (Eds), Handbook of research on the psychology of mathematics education. Past, present and future (pp. 461-494). Rotterdam: Sense Publishing.

RUTHVEN, K..Linking researching with teaching: Towards synergy of scholarly and craft knowlege. In: L.D. ENGLISH, L. D.; M. BARTOLINI-BUSI, M.; JONES, G. A.; R. LESH, R.;

TIROSHM, D. Handbook of International research in mathematics education,London: Lawrence Erlbaum Ass, 2002, p. 581-598

SKOVSMOSE, O. Cenários para Investigação. Bolema -Boletim de Educação Matemática.Rio Claro, n.14, set. 2000.

TALL, David. (1991). Recent development in the use of computer to visualize and symbolize calculus concept. In: Laboratory approach to teaching Calculus. v. 20, p. 15-25. Disponível em:http://homepages.warwick.ac.uk/staff/David.Tall/pdfs/dot1991i-comp-calc-

maa.pdf . Acessado em: 2 de Agosto 2013.

ZASLAVSKY, O., CHAPMAN, O.; LEIKIN, R. (2003). Professional development of mathematics educators: trends and tasks. In: BISHOP, A. J.; CLEMENTS, M. A.; KEITEL, C.; KILPATRICK, J.; LEUNG, F. K. S. (Eds.), Second international handbook of mathematics education (pp. 877-917). Dordrecht: Kluwer. 